\title{
Pontocerebellar hypoplasia type 4
}

INSERM

\section{Source}

INSERM. (1999). Orphanet: an online rare disease and orphan drug data base.

Pontocerebellar hypoplasia type 4. ORPHA:166063

Pontocerebellar hypoplasia type 4 ( $\mathrm{PCH} 4)$ is a very rare form of $\mathrm{PCH}$ (see this term),

characterized by prenatal onset of polyhydramnios and contractures followed by

hypertonia, severe clonus, primary hypoventilation leading to an early postnatal death. 